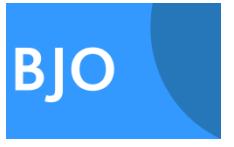

\title{
Counselling for people with sight loss in the UK: the need for provision and the need for evidence
}

Samuel Robert Nyman, Margot Ann Gosney and Christina Rita Victor

Br J Ophthalmol 2010 94: 385-386

doi: 10.1136/bjo.2009.159855

Updated information and services can be found at:

http://bjo.bmj.com/content/94/3/385.full.html

These include:

Email alerting Receive free email alerts when new articles cite this article. Sign up in the service box at the top right corner of the online article.

Notes

To order reprints of this article go to:

http://bjo.bmj.com/cgi/reprintform

To subscribe to British Journal of Ophthalmology go to:

http://bjo.bmj.com/subscriptions 
Table 1 Fungal organisms isolated from retrospective review of corneal ulcers from March-June $2004(n=54)^{*}$

\begin{tabular}{lcllc}
\hline Organisms & $\mathbf{n}(\%)$ & $\mathbf{M I C}_{\mathbf{5 0}}(\mu \mathbf{g} / \mathbf{m l})$ & $\mathbf{M I C}_{\mathbf{9 0}}(\mu \mathbf{g} / \mathbf{m l})$ & MIC $\mathbf{r a n g e ~}(\mu \mathbf{g} / \mathbf{m l})$ \\
\hline Aspergillus species & $24(44)$ & 32 & 64 & $8-64$ \\
$\quad$ Aspergillus flavus & $18(33)$ & 32 & 64 & $16-64$ \\
Aspergillus niger & $2(4)$ & - & - & $8-32$ \\
Aspergillus terreus & $3(6)$ & - & - & $8-32$ \\
Aspergillus fumigatus & $1(2)$ & - & - & $8-8$ \\
Fusarium species & $23(43)$ & 8 & 16 & $4-16$ \\
Unidentified hyaline species & $3(6)$ & - & - & $8-64$ \\
Acremonium species & $1(2)$ & - & - & 4 \\
Bipolaris species & $1(2)$ & - & - & 32 \\
Curvularia species & $2(4)$ & - & - & 4 \\
\hline
\end{tabular}

*For the complete baseline characteristics and MICs for all 98 isolates, see previously published data

MIC, minimum inhibitory concentration.

from presentation was considered a good result, and longer healing times a poor result. Logistic regression was used to predict a good/poor result, the primary outcome, using $\log _{2}$-transformed MIC as a covariate. The regression model was analysed using Pearson's goodness of fit. A Fisher's exact test was used to correlate genus (Aspergillus vs Fusarium) to good/poor result. All analyses were performed using STATA 9.2.

\section{RESULTS}

The baseline characteristics and MICs of 54 patients with fungal corneal ulcers are described in table 1.

A lower MIC was significantly associated with a good outcome, as was Fusarium species (as opposed to Aspergillus species) (table 2).

When restricted to a subgroup of organisms, for example Fusarium cases, the relationship between MIC and clinical outcome was similar in magnitude, but no longer statistically significant $(\mathrm{OR}=0.51$, $95 \%$ CI 0.12 to $2.05, \mathrm{p}=0.34$ ). In addition, when restricted to only Aspergillus cases, the relationship was neither significant nor similar in magnitude $(\mathrm{OR}=1.37,95 \%$ CI 0.39 to $4.88, p=0.63$ ).

\section{COMMENT}

Many factors contribute to the success or failure of fungal keratitis management, including ulcer size, ulcer location, organism, penetration of antimicrobial agent and susceptibility of the organism to treatment. In bacterial keratitis, studies suggest that susceptibility of the organism to the agent in vitro correlates with outcome. ${ }^{67}$ It remains unclear whether susceptibility correlates with outcome in fungal keratitis. ${ }^{8} 9$ In systemic fungal disease, researchers suggest that the role of susceptibility testing may be similar to that of bacterial susceptibility

testing, where approximately $90 \%$ of susceptible cases and $60 \%$ of resistant cases respond to therapy. ${ }^{1}$ Antifungal susceptibility testing is associated with outcome in mucosal candidiasis and candidaemia, and antifungal susceptibilities influence treatment recommendations. ${ }^{10}$

In fungal keratitis, in vitro susceptibility did correlate with outcome. A twofold increase in MIC was associated with a $47 \%$ reduction in the odds of healing. In addition, the organism is associated with outcome. Since only 54 of 90 cases with completed susceptibility testing had clinical data available, the study had limited generalisability. Further prospective studies would be necessary to assess whether MIC provides information useful to the clinician once the organism species has been identified, as well as the effect of other covariates such as toxicity, prior medications, age and sex.

\section{Brett L Shapiro, ${ }^{1}$ Prajna Lalitha, ${ }^{2}$ Allison R Loh, ${ }^{1,3}$ Annette W Fothergill, ${ }^{4}$ Namperumalsamy V Prajna, ${ }^{2}$ Muthiah Srinivasan, ${ }^{2}$ Amit Kabra, ${ }^{2}$ Jaya Chidambaram, ${ }^{1}$ Nisha R Acharya, ${ }^{1}$ Thomas M Lietman}

${ }^{1}$ F.I. Proctor Foundation, University of California, San Francisco, California, USA; ${ }^{2}$ Aravind Eye Hospitals, Madurai, India; ${ }^{3}$ University of Pennsylvania School of Medicine, Philadelphia, USA; ${ }^{4}$ University of Texas Health Sciences Center at San Antonio, Texas, USA

Correspondence to Dr Thomas M Lietman, F.I. Proctor Foundation, Room S309, 513 Parnassus Avenue, University of California, San Francisco, San Francisco, CA 94143, USA; tom.lietman@ucsf.edu

Acknowledgements The Department of Ophthalmology at UCSF is supported by a core grant from the National Eye Institute, EY02162, That Man May See and the South Asia Research Fund. In addition, this work was supported in part by a grant from the Doris Duke Charitable Foundation to UCSF to fund Clinical Research Fellow Allison Loh.

Table 2 Univariate analysis predicting healing at 3 weeks in fungal corneal ulcers $(n=54)$

\begin{tabular}{lll}
\hline Covariate & OR (95\% Cl) & p Value \\
\hline MIC $(\mu \mathrm{g} / \mathrm{ml})$ to natamycin & $0.53(0.32 \text { to } 0.86)^{*} \dagger$ & 0.01 \\
Fusarium (vs Aspergillus species) & $4.94(1.17$ to 22.3$)$ & 0.01 \\
\hline
\end{tabular}

${ }^{*}$ OR per twofold dilution in MIC

†Pearson's goodness of fit: $p=0.33$

MIC, minimum inhibitory concentration.
Funding The funding for this research was provided by the National Eye Institute, EY02162, That Man May See, the South Asia Research Fund and the Doris Duke Charitable Foundation. The funding organisations played no role in the design, collection, analysis and/or interpretation of data, writing or submission of the paper.

\section{Competing interests None.}

Ethics approval This study was conducted with the approval of the institutional review boards at Aravind Medical Research Foundation and University of California San Francisco (CHR \#H9332-21899-01).

Provenance and peer review Not commissioned; externally peer reviewed.

Accepted 23 April 2009

Br J Ophthalmol 2010;94:384-385

doi:10.1136/bjo.2009.158675

\section{REFERENCES}

1. $\mathbf{R e x} \mathbf{J H}$, Pfaller MA. Has antifungal susceptibility testing come of age? Clin Infect Dis 2002;35 982-9.

2. Lalitha $\mathbf{P}$, Prajna NV, Kabra A, et al. Risk factors for treatment outcome in fungal keratitis. Ophthalmologica 2006:113:526-30

3. Lalitha $\mathbf{P}$, Shapiro B, Srinivasan $\mathbf{M}$, et al. Antimicrobial susceptibility of Fusarium, Aspergillus and other filamentous fungi isolated from keratitis. Arch Ophthalmol 2007;125:789-93.

4. $\operatorname{Rex} \mathbf{J H}$, Alexander BD, Andes D, et al. Reference method for broth dilution antifungal susceptibility testing of filamentous fungi, approved standard. 2nd edn. (M38-A2). Wayne, PA, USA: Clinical and Laboratory Standards Institute (CLSI), 2008;28:16

5. Lalitha $\mathbf{P}$, Vijaykumar R, Prajna NV, et al. In vitro natamycin susceptibility of ocular isolates of Fusarium and Aspergillus species: comparison of commercially formulated natamycin eye drops to pharmaceutical-grade powder. J Clin Microbiol 2008:46:3477-8

6. Chen A, Lalitha P, Srinivasan M, et al. Does in vitro susceptibility predict clinical outcome in bacterial keratitis? Am J Ophthalmol 2007;145:409-12

7. Wilhelmus KR, Abshire RL, Schlech BA. Influence of fluoroquinolone susceptibility on the therapeutic response of fluoroquinolone-treated bacterial keratitis. Arch Ophthalmol 2003;121:1229-33.

8. Thomas PA, Abraham DJ, Kalavathy CM, et al. Oral itraconazole therapy for mycotic keratitis. Mycoses 1988;31:271-9.

9. O'Day DM, Ray WA, Robinson RD, et al. Correlation of in vitro and in vivo susceptibility of Candida albicans to amphotericin B and natamycin. Invest Ophthalmol Vis Sci 1987:28:596-603.

10. Marangon FB, Miller D, Giaconi JA, et al. In vitro investigation of voriconazole susceptibility for keratitis and endophthalmitis fungal pathogens. Am J Ophthalmol 2004;137:820-5.

Counselling for people with sight loss in the UK: the need for

\section{provision and the need for evidence}

For adults of any age the diagnosis of a visual impairment can be traumatic, and timely referral to informal peer support and/or 
professional counselling may be both beneficial and appropriate. It is estimated that $45 / 113$ (40\%) of UK voluntary organisations for people with sight loss provide professional counselling $(n=17)$ or 'informal support' $(n=28)$, such as peer support groups, telephone helplines and befriending. However, what is the evidence that these services help people adjust emotionally to their acquired vision loss and the consequences that flow from this?

During the spring/summer of 2008, we conducted a follow-up to the scoping survey reported earlier ${ }^{1}$ to assess the evidence for effectiveness of professional counselling services for people with acquired sight loss. We contacted the 17 counselling services previously identified by Rees $^{1}$ and further services via Vision 2020 UK, the National Association of Local Societies for Visually Impaired People, the Visual Impairment Network for Counselling and Emotional Support, and specialist ophthalmic nurses via the Royal College of Nursing. To evaluate the evidence for counselling services we requested the documentation used to support their development and copies of any evaluation reports.

We identified 28 services providing professional counselling in the UK for people with sight loss, 25 of which provided a service to a specific geographical area and three nationally by telephone. Counselling was rarely provided through the NHS or via social services $(8 / 28)$, and whilst free telephone-based counselling was available across the UK, the provision of free face-to-face counselling was patchy.

Six organisations initiated their services in response to a range of policy and research reports: a policy document outlining the provision of social services for visually impaired adults $(n=1)^{2}$ plus a low vision consensus forum document $(n=1)^{3}$, a research report by the Royal National Institute of Blind People (RNIB) $(n=2),{ }^{4}$ and an evaluation report by the RNIB showing promise for a face-to-face formal counselling service pilot service $(n=2) .^{5}$

Of the 28 counselling services, three were in the process of being evaluated, 11 had not been evaluated, 11 had collected client satisfaction data that would need to be updated and enhanced with validated scales, and three provided evaluation reports. Two of the three reports were of cross-sectional evaluations using client satisfaction data, but one report found that $100 \%$ of clients on completion of face-to-face counselling had reliably and significantly improved in emotional well-being, including a $41 \%$ reduction in mild risk of suicide. This pilot could be built upon with trials using more stringent controls of confounding variables and longer-term follow-up.

Our scoping survey was limited in that some services operating in the UK may not have been captured by our recruitment strategy. It is unclear whether these services provided formal counselling as $4 / 28$ services were not provided by qualified counsellors, $16 / 28$ organisations could not detail the training of their counsellors, and 11/28 could not characterise the type of counselling provided (eg humanistic, psychodynamic, etc). Our findings suggest that there is inequity in the provision of free face-to-face counselling to people with vision loss in the UK and that there has been little systematic evaluation of the counselling services available. The RNIB's pilot counselling services show promise, ${ }^{6}$ but their evaluations have yet to recruit control groups or assess longterm outcomes. We call upon researchers to evaluate emotional support services for people with sight loss to provide an evidencebase for their effectiveness in enhancing psychosocial well-being and to inform how these services can be improved. With this evidence voluntary organisations would receive greater recognition and funding for their emotional support services, thereby enhancing the quality of life of people with vision loss.

\section{Samuel Robert Nyman, ${ }^{1}$ Margot Ann Gosney, ${ }^{2}$ Christina Rita Victor ${ }^{1}$}

${ }^{1}$ School of Health and Social Care, University of Reading, Reading, UK; ${ }^{2}$ Institute of Health Sciences, University of Reading, Reading, UK

Correspondence to Dr Samuel R Nyman, School of Health and Social Care, University of Reading, Bulmershe Court, Reading RG6 1HY, UK; s.r.nyman@reading.ac.uk

Acknowledgements We thank the advisory group for this research: lain Hopkin (Thomas Pocklington Trust RGD Committee), Martin Leyland (Royal Berkshire NHS Foundation Trust, West Berkshire Community Hospital, and Oxford Eye Hospital), Angela McCullagh (Thomas Pocklington Trust), Mary Norowzian (RNIB) and Femi Nzegwu (Guide Dogs)

Funding This research was conducted whilst the first author was at the Institute of Health Sciences, and was commissioned and funded by Thomas Pocklington Trust.

\section{Competing interests None.}

Provenance and peer review Not commissioned; externally peer reviewed.

Accepted 24 April 2009

Br J Ophthalmol 2010;94:385-386.

doi:10.1136/bjo.2009.159855

\section{REFERENCES}

1. Rees L. Statistics for emotional support services questionnaires. Birmingham, UK: Birmingham Focus on Blindness, 2006:1-4.

2. Low Vision Services Consensus Group. Low vision services: recommendations for future service delivery in the UK. London: RNIB, 1999:18.

3. The Association of Directors of Social Services. Progress in sight: national standards of social care for visually impaired adults. London: Disabilities Committee of the Association of Directors of Social Services, 2002:43.

4. Nelson A. The individual support needs of older people with serious sight loss. London: RNIB, 2000:1-182.
5. Nicholls T. RNIB Bristol counselling project report: Department of Health section 64 funded project: September 2001-August 2004. Bristol, UK: RNIB, 2004:20-5.

6. Dale S. RNIB Bristol counselling project report: Department of Health section 64 funded project October 2005-June 2008. Bristol, UK: RNIB,2008:18-24.

\section{VSX2 in microphthalmia: a novel splice site mutation producing a severe microphthalmia phenotype}

Microphthalmia shows great genetic and clinical heterogeneity, whether as part of a syndrome or an isolated ocular phenotype. Chromosomal or single-gene disorders and teratogens may all cause microphthalmia. Associated syndromic features include cardiac problems, clefting, microcephaly and learning disabilities. ${ }^{1}$ Microphthalmia is frequently bilateral, but commonly asymmetrical in severity.

Homozygous mutations in VSX2/CHX10 have been demonstrated in human and murine microphthalmia. ${ }^{2}$ VSX2 is thought to act principally as a repressor of transcription, particularly of the genes encoding cyclin-dependent kinase inhibitor (p27 $7^{\text {kip1) }}$ and microphthalmia transcription factor (MITF). ${ }^{4}$ These repressive roles enable cell proliferation by preventing retinal progenitor cells from exiting the cell cycle, and by maintaining neuroretinal cell identity. Loss of these functions therefore causes failures in eye development. Other genes implicated in microphthalmia include $S O X 2, P A X 6$, sonic hedgehog $(S H H), R A X, O T X 2, C R Y B A$ and FOXE 3 . $^{1}$ Additional loci with no gene identified include 15q12-q15, $14 \mathrm{q} 32$ and Xq27-q28. ${ }^{1}$

Our patient has healthy first-cousin Turkish parents with no ocular anomalies, and an unaffected brother. Her very small eyes were noted at birth, but no other congenital anomalies. Her karyotype demonstrated 46, XX. Cranial MRI (see figure 1) confirmed severe microphthalmia and small optic nerves. Growth and development, given complete absence of vision, have progressed normally to her current age of 3.5 years. Neonatally, the right vestigial scleralised globe had no discernible anterior or posterior segment structures. The microphthalmic left globe had a clear cornea and formed anterior chamber but abnormally vascularised iris, with inferior colobomatous malformation. Light perception was absent on the right, and possibly present on the left. At age 3 years, the left eye remained severely microphthalmic (axial length $12.2 \mathrm{~mm}$ ) with no useful vision. The cornea remained clear, intraocular pressure was normal $(10 \mathrm{~mm} \mathrm{Hg})$, but leucocoria suggested a retrolental plaque. B-scan ultrasound revealed total retinal 